\title{
Asymmetrical Polymer Vesicles for Drug delivery and Other Applications
}

\author{
Yi Zhao ${ }^{1}$, Xiaoming $\mathrm{Li}^{1}$, Xiaotian Zhao ${ }^{1}$, Yunqi Yang ${ }^{1}$, Hui $\mathrm{Li}^{2 *}$, Xinbo Zhou ${ }^{3 *}$ and \\ Weien Yuan ${ }^{1 *}$
}

${ }^{1}$ School of Pharmacy, Shanghai Jiao Tong University, Shanghai, China, ${ }^{2}$ School of Medicine, University of California, San Francisco, San Francisco, CA, United States, ${ }^{3}$ Laboratory of Computer-Aided Drug Design and Discovery, Beijing Institute of Pharmacology and Toxicology, Beijing, China

OPEN ACCESS

Edited by:

Suowen Xu,

University of Rochester, United States

Reviewed by:

Christoph Eugen Hagemeyer,

Monash University, Australia

Zhiping Liu,

Augusta University, United States

*Correspondence:

Weien Yuan

yuanweien@126.com

Hui Li

talktohui@gmail.com

Xinbo Zhou

hapwave@163.com

Specialty section:

This article was submitted to

Translational Pharmacology,

a section of the journal

Frontiers in Pharmacology

Received: 20 March 2017

Accepted: 30 May 2017

Published: 20 June 2017

Citation:

Zhao Y, Li X, Zhao X, Yang Y, Li H,

Zhou X and Yuan W (2017)

Asymmetrical Polymer Vesicles for

Drug delivery and Other Applications.

Front. Pharmacol. 8:374.

doi: 10.3389/fphar.2017.00374
Scientists have been attracted by polymersomes as versatile drug delivery systems since the last two decades. Polymersomes have the potential to be versatile drug delivery systems because of their tunable membrane formulations, stabilities in vivo, various physicochemical properties, controlled release mechanisms, targeting abilities, and capacities to encapsulate a wide range of drugs and other molecules. Asymmetrical polymersomes are nano- to micro-sized polymeric capsules with asymmetrical membranes, which means, they have different outer and inner coronas so that they can exhibit better endocytosis rate and endosomal escape ability than other polymeric systems with symmetrical membranes. Hence, asymmetrical polymersomes are highly promising as self-assembled nano-delivery systems in the future for in vivo therapeutics delivery and diagnostic imaging applications. In this review, we prepared a summary about recent research progresses of asymmetrical polymersomes in the following aspects: synthesis, preparation, applications in drug delivery and others.

Keywords: asymmetrical polymer vesicle, drug delivery, self-assemble, nano-delivery vesicles

\section{INTRODUCTION}

Polymersomes, which also can be called polymeric vesicles, have attracted scientists' interests in recent years. Compared to other nanometer scale self-assembling delivery systems, such as polymer micelles, nanoparticles and nanogels, polymersomes provide a more stable condition for the storage of drugs, especially for nanoscopic emulsions (Asano et al., 2016). As compared to similar devices such as liposomes, which are comprised of low molecular weight lipids, polymersomes are composed of versatile macromolecular amphiphiles architectures, including dendritic copolymers (Yang et al., 2005), graft polymers (Dou et al., 2003; Lee et al., 2006), amphiphilic diblock polymers (Discher et al., 1999; Qin et al., 2006; Zhou et al., 2006), triblock polymers (Nardin et al., 2000; Napoli et al., 2004a) and so on. Because of this unique composition, polymersomes commonly exhibit much better colloidal stability, solidity, and protection of drugs, whereas illustrating very little chemical permeability. Composed of amphiphilic $\mathrm{AB}$ diblock or $\mathrm{ABC}$ triblock copolymers, polymersomes usually have relatively longer hydrophobic blocks to make up the dense core membranes, and shorter hydrophilic blocks in the facial membranes to protect the interior fluids in aqueous solutions. Hence, this advantage presents an excellent solution to the problem that no matter what hydrophilic or hydrophobic property a particular drug has, polymersomes can act as appropriate carriers for the drug. For example, both hydrophobic (e.g., doxorubicin, paclitaxel, quantum dots) and hydrophilic molecules (e.g., DNA, siRNA, therapeutic proteins, chelated Gd) can be encapsulated into polymersomes (Wang et al., 2012; Anajafi et al., 2017; Nomani et al., 2017). 
As we all know, for a drug carrier, biodegradability is the first thing that must be considered carefully (Zhao et al., 2014). The alternative hydrophobic block-based drug carrier systems, such as liposomes, must be decorated with poly(ethylene glycol) (PEG) or polycarbonates in order to maintain a stealthy property. PEG is the most commonly used material for decorating drug carriers because it can maintain the carriers' stability in the plasma by prohibiting the adsorption of plasma proteins and has little toxicity to the cells (Kricheldorf, 2006). Hence, the carriers whose surfaces are decorated with PEG chains usually get longer blood circulation times (Gref et al., 2000; Ohya et al., 2011). However, this will not be a problem for polymersomes. Taking the advantage of the arbitrary structures, polymersomes can be intrinsically stealthy, because they present typical hydrophilic macromolecular amphiphilic parts (e.g., PEG and dextran) in the facial membranes. This non-fouling property offers scientists a great convenience to make further transformation. Though polymersomes have the above advantages over liposomes, polymersomes have relatively low loading levels and loading efficacies for hydrophilic drugs, including protein drugs and chemotherapeutics, which limits their applications as drug carriers, especially for anti-tumor therapy. To investigate this issue, great efforts have been made to improve the loading efficiency of polymersomes. It is a normal way to decorate polymersomes with specific ligands to create smart polymersomes, which selectively releases payloads to the sites of action in response to external stimulus (e.g., magnetic and photo) or internal signals (e.g., enzyme degradation, endo/lysosomal $\mathrm{pH}$ and cytoplasmic glutathione). Decorated materials usually include aptamers, lactoferrin, antibodies, peptides, and folate (Lu et al., 2015). Moreover, changing the permeability of the membranes, or controlling the degradability of the structures can also achieve the same effect (LoPresti et al., 2009). In addition, ingenious encapsulation procedures such as nano-precipitation method (Sanson et al., 2010) and transmembrane phosphate-, citrate-, sulfate-, or PH- gradient loading (Choucair et al., 2005; Ahmed et al., 2006a; Yin et al., 2009; Gubernator, 2011) are also smart ways to enhance the loading efficacy.

Lo Presti et al. have demonstrated that by exploiting endocytosis, $\mathrm{pH}$-sensitive PMPC-PDPA polymersomes can deliver various drugs effectively to cells (Lomas et al., 2007, 2008; Massignani et al., 2009, 2010a; Murdoch et al., 2010). There exists different mechanisms that control the acidification of the internalized material within subcellular compartments (endosomes) (Doherty and McMahon, 2009). The authors have also found that after polymersomes are internalized by endocytosis, they will disassemble in a controllable manner when approaching the acidic endosomal lumen. This, conversely, leads to endosomal membrane perturbation in a short time, which will facilitate the polymersomes to escape from endosomes and get into the cell cytosol (Lomas et al., 2007, 2008; Massignani et al., 2009). The endocytosis efficiency is strongly dependent on the polymersome topology and surface chemistry, as well as the polymersome size (Massignani et al., 2009).

Although the difficulty can be conquered in various ways, it still remains a big challenge that symmetrical polymersomes exhibit inefficient intracellular drug delivery. First of all, as symmetrical polymersomes-based drug delivery systems show low endosomal escape ability, they may be trapped inside the endosomes. Besides, the side effects to healthy cells due to the slow endocytosis rate and drug diffusion can never be neglected. In recent years, asymmetric polymersomes have attracted a lot of attention in the drug delivery field. They have the following advantages: efficient drug loading capacity, fast endocytosis rate and endosomal escape ability, which can meet most requirements for drug delivery (Liu et al., 2014). Asymmetrical vesicles with different structures both inside and outside are self-assembled from asymmetric $\mathrm{ABC}$ triblock copolymers or $\mathrm{AB}$ and $\mathrm{BC}$ two diblock copolymers ( $\mathrm{Lu}$ et al., 2015). In this review, we prepared a summary about recent progresses of asymmetrical polymersomes in the following aspects: synthesis, preparation, applications in drug delivery and others.

\section{SYNTHESIS AND PREPARATION OF ASYMMETRICAL POLYMERSOMES}

\section{Synthesis of Asymmetric Triblock Copolymers}

There are two methods to synthesize the materials of polymersomes. One is mixing $\mathrm{AB}$ and $\mathrm{BC}$ diblock copolymers together, the other is directly using $\mathrm{ABC}$ triblocks to form asymmetrical polymersomes. Consisting of at least two homopolymer blocks, block copolymers are the ideal materials for forming self-assembling polymersomes. Normally, the homopolymer is designed to exhibit some specific physicochemical properties, and in consequence, the block copolymers will display versatile properties and utilization values (Lee and Feijen, 2012; Ge et al., 2014).

Sequential radical addition-fragmentation chain transfer (RAFT) polymerization is the most commonly used technique to synthesis triblock copolymers (Du et al., 2012). Ringopening polymerization (ROP) is another feasible way to synthesize diblock or triblock copolymers (Kishimura et al., 2007). The properties of the diblock or triblock copolymers can determine the types and applications of the asymmetrical polymersomes by controlling the structures, compositions and molecular weights ( $\mathrm{Li}$ et al., 2015). Therefore, we summarize some available diblock or triblock copolymers that constitute asymmetrical polymersomes, and the results are given in Table 1.

\section{Preparation of Asymmetrical Polymersomes}

There are two major methods to form self-assembling asymmetrical polymersomes: solvent change method (phase inversion) and direct hydration method (Zhang and Eisenberg, 1995; Blanazs et al., 2009). The first method is more widely used. Interestingly, Asano et al. first used the co-assembly method to generate asymmetric polymersomes. They put two distinct diblock copolymers PS-b-PEO (SO) and PB-b-PEO (BO) in an oil-in-oil emulsion $\mathrm{PS} / \mathrm{PB} / \mathrm{CHCl}_{3}$ (Asano et al., 2016). 
TABLE 1 | Examples of available diblock or triblock copolymers that constitute asymmetrical polymersomes.

\begin{tabular}{|c|c|c|c|c|c|c|c|}
\hline Polymers & $\begin{array}{l}\text { Preparation } \\
\text { method }\end{array}$ & $\begin{array}{l}\text { Formation } \\
\text { method }\end{array}$ & Copolymers & $\begin{array}{l}\text { Targeting } \\
\text { ligands }\end{array}$ & $\begin{array}{l}\text { Drugs/stimulus } \\
\text { for release }\end{array}$ & Pros and cons & References \\
\hline $\begin{array}{l}\text { PEO45-b-PS130- } \\
\text { b-PDEA120 }\end{array}$ & Atrp & None reported & $\begin{array}{l}\text { PEO45-b-PS130-b- } \\
\text { PDEA120 }\end{array}$ & $\begin{array}{l}\text { None } \\
\text { reported }\end{array}$ & $\mathrm{pH}$-induced & None reported & $\begin{array}{l}\text { Giacomelli et al., } \\
2007\end{array}$ \\
\hline $\begin{array}{l}\text { FA/DTPA-PGA-b- } \\
\text { PCL }\end{array}$ & $\begin{array}{l}\text { None } \\
\text { reported }\end{array}$ & $\begin{array}{l}\text { Solvent } \\
\text { switching } \\
\text { method }\end{array}$ & $\begin{array}{l}\text { FA-PGA75-b-PCL30 } \\
\text { and } \\
\text { DTPA-PGA22-b-PCL30 }\end{array}$ & FA & $\begin{array}{l}\mathrm{DOX} \cdot \mathrm{HCl} / \mathrm{pH}- \\
\text { induced }\end{array}$ & $\begin{array}{l}\text { Improve the sensitivity of } \\
\text { a T2 MRI contrast agent }\end{array}$ & $\begin{array}{l}\text { Oerlemans et al., } \\
2010\end{array}$ \\
\hline $\begin{array}{l}\text { PEG5K-P(CL-CO- } \\
\text { LA)11K-PEG2K }\end{array}$ & Rop & $\begin{array}{l}\text { Film hydration } \\
\text { method }\end{array}$ & $\begin{array}{l}\text { mPEG-PCL or } \\
\text { mPEG-P-(CL-Co-LA) }\end{array}$ & $\begin{array}{l}\text { None } \\
\text { reported }\end{array}$ & $\mathrm{Hb}$ & $\begin{array}{l}\text { Undamaged gas-binding } \\
\text { capability and oxygen } \\
\text { affinity, plus high stability } \\
\text { and biocompatibility }\end{array}$ & $\begin{array}{l}\text { Kishimura et al., } \\
2007\end{array}$ \\
\hline $\begin{array}{l}\text { PEO113-b- } \\
\text { PCL132-b-PAA15 }\end{array}$ & $\begin{array}{l}\text { None } \\
\text { reported }\end{array}$ & $\begin{array}{l}\text { Solvent } \\
\text { switching } \\
\text { method }\end{array}$ & $\begin{array}{l}\text { PEO113-b-PCL132-b- } \\
\text { PAA15 }\end{array}$ & $\begin{array}{l}\text { None } \\
\text { reported }\end{array}$ & $\begin{array}{l}\mathrm{DOX} \cdot \mathrm{HCl} / \mathrm{pH}- \\
\text { induced }\end{array}$ & $\begin{array}{l}\text { High DOX loading } \\
\text { efficiency and good } \\
\text { biodegradability, rapid } \\
\text { endocytosis rate and } \\
\text { endosomal escape ability }\end{array}$ & Liu et al., 2014 \\
\hline $\begin{array}{l}\text { Acupa-PEG- } \\
\text { PTMBPEC-PSAC }\end{array}$ & Rop & $\begin{array}{l}\text { Solvent } \\
\text { switching } \\
\text { method }\end{array}$ & $\begin{array}{l}\text { Acupa-PEG-PTMBPEC- } \\
\text { PSAC and } \\
\text { PEG-PTMBPEC-PSAC }\end{array}$ & $\begin{array}{l}\text { 2-[3-[5- } \\
\text { amino-2- } \\
\text { carboxypentyl]- } \\
\text { ureido]- } \\
\text { pentanedioic } \\
\text { acid }\end{array}$ & $\begin{array}{l}\mathrm{GrB} / \mathrm{pH}- \\
\text { induced }\end{array}$ & $\begin{array}{l}\text { Unimodal distribution, } \\
\text { high protein loading } \\
\text { contents, long circulation } \\
\text { time }\end{array}$ & Du et al., 2012 \\
\hline $\begin{array}{l}\text { PEG-SS-PCL- } \\
\text { PDEA }\end{array}$ & Rop & $\begin{array}{l}\text { Solvent } \\
\text { switching } \\
\text { method }\end{array}$ & $\begin{array}{l}\text { PEG-PCL-PDEA and } \\
\text { PEG-SS-PCL }\end{array}$ & Galactose & $\begin{array}{l}\text { GrB/reduction- } \\
\text { induced }\end{array}$ & $\begin{array}{l}\text { Unimodal distribution, } \\
\text { highly efficient loading, } \\
\text { high protein loading } \\
\text { contents, long circulation } \\
\text { time, target ability }\end{array}$ & $\begin{array}{l}\text { Drummond et al., } \\
1999\end{array}$ \\
\hline PB-b-PS & Atrp & $\begin{array}{l}\text { Blending in an } \\
\text { oil-in-oil } \\
\text { emulsion }\end{array}$ & $\begin{array}{l}\text { polystyrene-b- } \\
\text { poly(ethylene oxide) (SO) } \\
\text { and polybutadiene-b- } \\
\text { poly-(ethylene oxide) } \\
\text { (BO) }\end{array}$ & $\begin{array}{l}\text { None } \\
\text { reported }\end{array}$ & None reported & $\begin{array}{l}\text { Straightforward } \\
\text { preparation method }\end{array}$ & Asano et al., 2016 \\
\hline $\begin{array}{l}\text { PEG-PAA(SH)- } \\
\text { PDEA) }\end{array}$ & Raft & $\begin{array}{l}\text { Solvent } \\
\text { switching } \\
\text { method }\end{array}$ & PEG-PAA(SH)-PDEA) & $\begin{array}{l}\text { None } \\
\text { reported }\end{array}$ & $\begin{array}{l}\text { FITC- } \\
\mathrm{CC} / \text { reduction- } \\
\text { and } \\
\mathrm{pH} \text {-induced }\end{array}$ & $\begin{array}{l}\text { Conveniently prepared, } \\
\text { high loading content, } \\
\text { excellent biocompatibility }\end{array}$ & $\begin{array}{l}\text { Zupancich et al., } \\
2006\end{array}$ \\
\hline PEO-PAA-PNIPAM & Raft & $\begin{array}{l}\text { Solvent } \\
\text { switching } \\
\text { method }\end{array}$ & PEO-PAA-PNIPAM & $\begin{array}{l}\text { None } \\
\text { reported }\end{array}$ & $\begin{array}{l}\text { FITC-dextran/ } \\
\text { temperature- } \\
\text { induced }\end{array}$ & $\begin{array}{l}\text { Stability against high salt } \\
\text { conditions and change of } \\
\text { temperature }\end{array}$ & $\begin{array}{l}\text { Du and O'Reilly, } \\
2009\end{array}$ \\
\hline $\begin{array}{l}\text { PEO-PDPA- } \\
\text { PDMA }\end{array}$ & Atrp & $\begin{array}{l}\text { Solvent } \\
\text { switching } \\
\text { method }\end{array}$ & PEO-PDPA-PDMA & $\begin{array}{l}\text { None } \\
\text { reported }\end{array}$ & None reported & None reported & $\begin{array}{l}\text { Zhang and } \\
\text { Eisenberg, } 1995\end{array}$ \\
\hline PEG-PCL-PDEA & Raft & $\begin{array}{l}\text { Film hydration } \\
\text { method }\end{array}$ & PEG-PCL-PDEA & $\begin{array}{l}\text { None } \\
\text { reported }\end{array}$ & FITC-CC & $\begin{array}{l}\text { High protein loading } \\
\text { efficiencies and } \\
\text { controlled release, able } \\
\text { to simultaneously deliver } \\
\text { and release hydrophobic } \\
\text { anticancer drugs and } \\
\text { proteins into cells }\end{array}$ & Liu et al., 2010 \\
\hline PEG-PCL-DEX & Rop & $\begin{array}{l}\text { Solvent } \\
\text { switching } \\
\text { method }\end{array}$ & PEG-PCL and DEX-PCL & $\begin{array}{l}\text { None } \\
\text { reported }\end{array}$ & PEO & $\begin{array}{l}\text { A variety of chemically } \\
\text { dynamic characteristics } \\
\text { responding to biological } \\
\text { pathways }\end{array}$ & Zhang et al., 2010 \\
\hline
\end{tabular}




\section{DRUG DELIVERY BY ASYMMETRIC POLYMERSOMES}

As mentioned above, compared with liposomes, polymersomes have more robust membranes, thus can improve the circulation half-life, protect drugs and prevent uncontrolled drug release. However, the rate and spatial distribution cannot be controlled because of the restriction of the structures (Mecke et al., 2006). Therefore, polymersomes that can response to various stimuli are developed by changing the physical and chemical properties of the membranes of the polymersomes (Du and O'Reilly, 2009; Onaca et al., 2009; van Dongen et al., 2009). As a consequence, the side effects are reduced and the efficacy of drugs at the site of action is improved. The stimuli can be classified into two aspects: external stimuli (temperature change, UV light and magnetic field) and intracellular stimuli ( $\mathrm{pH}$, redox).

\section{Temperature-Responsive Asymmetric Polymersomes}

Compared with UV stimuli for drug release, temperature stimuli are a more practicable way for building intelligent polymersomes, since natural temperature differences in tissues exist in human body. Tumor tissues have a higher temperature than normal tissues and the temperature can change easily in the external, such as hyperthermia (Xu et al., 2009). Furthermore, using the heating or cooling appliances for particular sections of the body can also achieve the effect of temperature differences (Christian et al., 2009).

The temperature-dependent mechanisms can be achieved by using the polymer poly(N-isopropylacrylamide) (PNIPAm) (Li et al., 2006; Qin et al., 2006). PNIPAm has a unique property that its conformation will change if the temperature is above the lower critical solution temperature (LCST) of PNIPAm $\left(40^{\circ} \mathrm{C}\right)$. Above $40^{\circ} \mathrm{C}$, the block will change its property from hydrophilic to hydrophobic. Thus, temperature-sensitive polymersomes are designed by using PNIPAm. Usually, PNIPAm chains are covalently combined with a hydrophilic block such as poly $(\mathrm{N}$ (3-aminopropyl) methylacrylamide hydrochloride) (PAMPA) or PEO. The resulting copolymer will self-assemble to form polymersomes and have the capacity to load hydrophilic drugs. If the temperature decreases below $40^{\circ} \mathrm{C}$, the polymersomes will disassemble to the former copolymer and release the encapsulated therapeutics. Cai et al. (2011) prepared asymmetric polymersomes based on poly(ethylene oxide)-b-poly(ethylene oxide-stat-butylene oxide)-b-poly(isoprene) (E-BE-I) ABC triblock copolymer, which presented the temperature dependent property and the LCST was $25^{\circ} \mathrm{C}$. Compared to the usual temperature-responsive polymersomes using PNIPAm as responsive factors, these polymersomes had narrower molecular weight distribution and faster transformation rate because of the lacking of strong interchain hydrogen bonding (Figure 1).

\section{pH-Responsive Asymmetric Polymersomes}

As a matter of fact, in the tumor microenvironment there is an innate $\mathrm{pH}$ difference $(\mathrm{pH}$ 6.5-7.2) and the cancer cells' endosomes and lysosomes are acidic ( $\mathrm{pH} 4.0-6.5)$ (Grabe and Oster, 2001; Rofstad et al., 2006; Meng et al., 2014). Ahmed et al. found that a number of polymersomes approached cellular endolysosomes by pinocytosis passageway (Ahmed et al., 2006b). Hence, this intracellular cue can be applied for $\mathrm{pH}$-dependent asymmetric polymersomes. This release method has an advantage over external cues (temperature, UV) owing to the accessibility of such intracellular cues. Using polymersomes whose structures are susceptibility to this $\mathrm{pH}$ difference, targeted intracellular release of the specific encapsulated cargo can be achieved. $\mathrm{Du}$ et al. investigated endosomal $\mathrm{pH}$-sensitive degradable asymmetric polymersomes constructed by $\mathrm{ABC}$ triblock poly(ethylene glycol)-b-poly(trimethoxybenzylidene tris (hydroxymethyl)ethane methacrylate)-b-poly(acrylic acid) (PEG-PTTMA-PAA). In this study, they demonstrated that PTTMA block could quickly destabilize due to the degradation of acetal groups in lower $\mathrm{pH}$ in the endo/lysosomal compartments of cancer cells, achieving targeted intracellular release of $\mathrm{DOX} \cdot \mathrm{HCl}$ and high anti-tumor therapeutic effects (Du et al., 2012).

\section{Redox-Responsive Asymmetric Polymersomes}

Oxidation (Napoli et al., 2004b,a) or reduction-responsive (Cerritelli et al., 2007) reactions open up new spatial release mechanisms in the human body (Bodor, 1987; Corti et al., 2010). Oxidative environments exist at sites of inflammation, tumor tissues and in extracellular fluids, as well as intracellular compartments such as the endolysosomes (Grundl, 1994; Tew, 2007).

Wang et al. (2013) demonstrated reduction-responsive asymmetrical polymersomes based on PEG-SS-PCL diblock copolymer and asymmetric PEG-PCL-PDEA triblock copolymer. When exposed to reducing environments such as the nuclei and cytoplasm of cancer cells, this system will quickly rupture due to cleavage of the disulfide bonds between PEG and PCL blocks. This delivery system can protect encapsulated cargos in the extracellular environments (i.e., blood plasma) and induce efficient intracellular drug release, therefore it has the potential to be a versatile and multifunctional drug delivery platform by using intracellular stimuli (Krack et al., 2008).

\section{APPLICATIONS OF ASYMMETRIC POLYMERSOMES}

Polymersomes have higher stability than liposomes (Discher et al., 1999; Photos et al., 2003; Lee et al., 2011). Moreover, polymersomes not only can encapsulate hydrophilic drugs but also can hold hydrophobic or amphiphilic compounds into their lumina or membranes. This advantage can be used in the fields of drug delivery, medical imaging and disease diagnosis (Massignani et al., 2010b). It has been proved that anticancer drugs (i.e., PTX and DOX.HCl) (Ahmed et al., 2006a; Chen et al., 2010), membrane proteins (i.e., OmpF, LamB, and FhuA, Stoenescu et al., 2004), hydrophobic dyes (i.e., PKH26) (Photos et al., 2003) and amphiphilic dyes (i.e., octadecyl rhodamine B, 


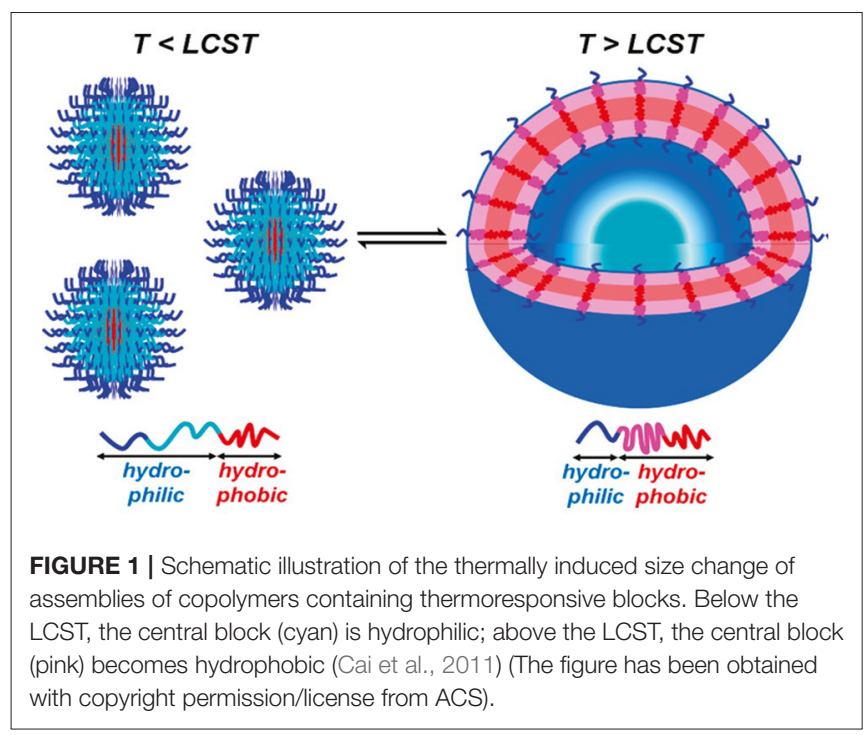

Battaglia and Ryan, 2005; Lomas et al., 2008) can be incorporated into membranes of polymersomes.

\section{Delivery of Conventional Drugs}

Encapsulating drugs in asymmetric polymersomes can achieve efficient drug loading capacity, fast endocytosis rate and rapid endosomal escape ability. All of these advantages help to maintain the property of drugs in vivo or in vitro and control the release rate. With the development of smart delivery systems, many cancer-target chemotherapeutics drugs which have severe side effects now come to a renascence (Arrigo, 2000, 2005; Arrigo and Ducasse, 2002).

Liu et al. reported $\mathrm{pH}$-sensitive asymmetric polymersomes based on PEO-b-PCL-b-PAA triblock copolymer. PEO chains constituted the outer corona of polymersomes because it showed well-behaved biocompatibility and was intrinsically stealthy to immune system. The $\mathrm{pH}$-responsive PAA chains were designed in inner aqueous core since they could quickly destabilize at endosomal pH. Consequently, the release of encapsulated cargos in the cells was efficient and accurate (Liu et al., 2014).

\section{Delivery of Protein}

Protein drugs have been recognized as one kind of the most potential leads for the growth of new therapeutics (Tan et al., 2010), and they are powerful antidotes toward many intractable diseases such as diabetes and cancers (Torchilin and Lukyanov, 2003; Futaki, 2006; Schrama et al., 2006). However, they are too sensitive to environmental conditions, which results in their short lives in vivo.

Polymersomes with huge aqueous compartments can encapsulate proteins and the membranes will protect proteins from degradation (Discher et al., 2007; Christian et al., 2009; Sun et al., 2009; Meng and Zhong, 2011; Lee and Feijen, 2012; Liu et al., 2012). So far, polymersomes have encapsulated a variety of proteins, including aquaporin $\mathrm{Z}$ (Kumar et al., 2007), cytochrome C (CC) (Hvasanov et al., 2011), hemoglobin
(Rameez et al., 2008; Li et al., 2012), insulin (Xiong et al., 2007; Christian et al., 2009; Kim H. et al., 2012), immunoglobulin G (Fu et al., 2011), ovalbumin (Stano et al., 2013), and myoglobin (Kishimura et al., 2007). Recent investigations also have found that polymer vesicles with asymmetrical membranes exhibit much higher loading capacity of proteins than symmetrical polymersomes.

$\mathrm{Li}$ et al. reported self-aggregated vesicles with asymmetric membranes. These polymersomes can serve as hemoglobin ( $\mathrm{Hb}$ )-based oxygen carriers with oxygen affinity and high $\mathrm{Hb}$ loading content and meanwhile no interference with blood cells. Further studies have shown that these vesicles have great stability and efficacy, which have the potential to be alternative blood substitutes (Li et al., 2014).

\section{Theranostic Vesicles for Magnetic Resonance Imaging}

Magnetic resonance imaging (MRI) is a widespread diagnosis apparatus that is clinically used for taking pictures of organs and structures inside the body to find blood vessels, bleeding, tumors or infection. Using asymmetric polymersomes to deliver contrast agents has better sensitivity and lower toxicity. Liu et al. (2015) reported asymmetrical polymersomes based on two kinds of diblock copolymer FA-PGA75-b-PCL30 and DTPAPGA22-b-PCL30, which had diagnostic and therapeutic effects simultaneously. The highest drug DLE can reach $52.6 \%$ and the T1 relaxivity can be increased by 8 -fold, meanwhile maintaining a low toxicity and remarkable positive contrast enhancement for tumor imaging.

\section{Applications of Non-spherical Shape Asymmetric Polymersomes}

Polymersomes with non-spherical shapes play important roles in applications such as vaccine development. Non-spherical shape can cause different interaction to immune cells because the shapes determine the in vivo behavior of polymersomes. Actually, there are not comprehensive studies that investigated the influence of shape and topology on the in vivo behavior of polymersomes.

Researchers have found that tubular structures are one of the most promising morphologies rather than spheres. Owing to the resembling with bacterial topologies, tubular structures offer larger contact areas between particles and cells. Van Hest's group has developed a series of methods that reshaped spherical vesicles to tubular structures. The ability of tunable membrane gives these spherical structures a chance to apply to the immunology field (Williams et al., 2017). As for polymersomes, not only the copolymer composition can influence the morphology but also the response to various stimuli such as temperature, $\mathrm{pH}$, magnetic fields, or osmotic pressure can further change the structures. In a recent example by van Hest et al. (Abdelmohsen et al., 2016a), the formation of functional nanotubes from PEGPDLLA was demonstrated. Biodegradable polymersomes made by PEG-PDLLA copolymer transformed their structures from spheres to nanotubes upon dialysis under hypertonic conditions. Owing to the dialysis with the increasing concentration of $\mathrm{NaCl}$, 
the size can be osmotically controlled by the enrichment and elongation of the structures. In this way, such well-defined nanoparticles can be easily prepared and functionalized. This method established a novel platform for biomedical research where nanoscopic control over size and shape is highly valuable. Another example of non-spherical vesicles is the stomatocytes, which can also be prepared by dialysis. Through shape transformation of spherical polymersomes into bowl-shaped stomatocytes, polymersomes will form an extra nanocavity. Due to the direct contact with the outside environment, these vesicles present the ability to convert chemical energy into kinetic energy when encapsulating enzymes or catalytic nanoparticles in the nanocavity. Further investigations showed that stomatocytes have the chemotactic ability toward certain cell types (Williams et al., 2017). Stomatocytes are promising candidates for further useful applications such as immunoassays, protein and DNA isolation, detection and biosensing (Abdelmohsen et al., 2016b).

\section{Applications of Targeting Polymersomes}

Much efforts have been made for targeting drugs and genes to specific sites. It is crucial for clinical therapeutics because drugs without targeting ability may cause low effect and high toxicity. Targeted delivery is categorized into two types: active targeting and passive targeting. Passive targeting aims at capturing nanoparticles that are smaller than the aperture gap of endothelial cells. These nanoparticles can go through the interstitium and therefore gather in tumor tissue (Danhier et al., 2009). Active targeting takes advantage of molecular recognition to transport drugs to specific sites. Attaching biological ligands or antibodies to the nanoparticles is the most widely applied method and it is usually carried out by chemically conjugating (Yang et al., 2002; Li et al., 2005; Rerat et al., 2010), mixing (Guo et al., 2009) and coating (Yang et al., 2002; Elloumi Hannachi et al., 2009). Targeting moieties are usually conjugated to the hydroxyl groups of their hydrophilic polymer blocks (e.g., PEO, PEG) (Torchilin et al., 2001; Velonia et al., 2002; Levine et al., 2008). In addition, polymersomes conjugated with targeting moieties may change their hydrophilic-block-to-total-mass ratio, resulting in the change of morphology. For example, from vesicles to micelles.

Lu et al. reported the modification of their triblock copolymer (PEG-PTTMA-PAA) polymersomes with anisamide (Anis) to target the cancer cell receptor sigma (Lu et al., 2015). Sigma receptor is an over-expressed membrane protein that appears in many human malignant diseases including lung cancer and prostate cancer ( $\mathrm{Lu}$ et al., 2015). Anis ligands exhibit high affinity to sigma receptor and so far have been used as guides to deliver versatile drugs including proteins, siRNAs and doxorubicin (Della Rocca et al., 2011; Guo et al., 2012; Kim S. K. et al., 2012). Their results validated that Anis-chimaeric polymersomes (CPs) presented high targeting ability to H460 and when Anis contents increased, antitumor efficacy was improved. If competitive antagonist is used, the antitumor activity will be reduced drastically (Lu et al., 2015).

\section{Applications of Leukopolymersomes}

Many polymersomes are easily internalized by endocytosis of macrophages and induce inflammatory responses. Therefore, polymersomes are often designed to be biodegradable and biocompatible and with reduced in vivo inflammatory responses.

Leukopolymersomes are a kind of polymersomes that have adhesive properties to leukocytes. It can be easily made by just functionalizing the terminal groups on the membranes of the vesicles. There are two typically adhesive ligands on leukocytes, which are named as selectins and integrin. These two ligands can mimic the adhesive properties of activated leukocytes (Hammer et al., 2008). Engineered to express the adhesion molecules, leukopolymersomes can achieve binding to inflammatory substrates in the shear fluid flow in blood vessels (Hammer et al., 2008). Moreover, by altering the membrane materials and ligand ratio, the rate and type of adhesive interaction can be tuned. Hammer et al. demonstrated that the adhesion was specific because the adhesive rate was the same as that of leukocytes (Hammer et al., 2008).

The adhesiveness of leukopolymersomes can be coupled with other properties of polymersomes, such as their ability to encapsulate drugs and image contrast agents. These particles will ultimately be useful for creating theranostic particles that can detect, image and deliver drugs to inflammatory sites, cancer cells, and cardiovascular lesions (Robbins et al., 2010).

\section{CONCLUSIONS}

In this review, we summed up the recent progresses of asymmetrical polymersomes from the aspects of preparation, delivery, applications and targeting of asymmetrical polymersomes. Asymmetrical polymersomes with asymmetrical membranes and large watery cores can encapsulate various therapeutic molecules including both hydrophilic and hydrophobic molecules. Their tunable membrane formulations, stability in vivo, various physicochemical properties, controlled release mechanisms, and targeting ability make asymmetrical polymersomes one of the most ideal platforms for drug delivery. According to many recent papers, we have found that a large number of examples showing polymersomes research has caught up with liposomal science in the past decade and in many cases, adding extra dimensions to what is possible. In the future, more research should be performed to further improve the following aspects of asymmetrical polymersomes: (1) increasing the loading capacity and encapsulation rate of drugs into asymmetrical polymersomes; (2) enhancing the efficiency of controlled release with the goal of achieving zero-order release and stimuli-responsive release; (3) improving the delivery efficiency of macromolecular therapeutics such as protein and nucleic acid drugs; (4) improving the in vivo circulation half-life and the efficiency for specifically targeted drug delivery.

\section{AUTHOR CONTRIBUTIONS}

YZ, XL, XZ, YY, HL, XZ, and WY: conceived and participated in its design, searched databases, extracted and assessed studies and helped to draft the manuscript. WY: conceived the initial idea and the conceptualization, participated in the data extraction and analysis, and revised the manuscript. XZ and HL: participated in 
the conceptualization and design of the study and analysis, and YZ: wrote the manuscript. All authors read and approved the final manuscript.

\section{ACKNOWLEDGMENTS}

The study was supported by the Projects of National Science Foundation of China (No. 81373366), the Projects of National

\section{REFERENCES}

Abdelmohsen, L. K., Nijemeisland, M., Pawar, G. M., Janssen, J. G. A., Nolte, R. J., et al. (2016b). Dynamic loading and unloading of proteins in polymeric stomatocytes: formation of an enzyme-loaded supramolecular nanomotor. ACS Nano 10, 2652-2660. doi: 10.1021/acsnano.5b07689

Abdelmohsen, L. K., Williams, D. S., Pille, J., Ozel, S. G., Rikken, R. S., Wilson, D. A., et al. (2016a). Formation of well-defined, functional nanotubes via osmotically induced shape transformation of biodegradable polymersomes. J. Am. Chem. Soc. 138, 9353-9356. doi: 10.1021/jacs.6b03984

Ahmed, F., Pakunlu, R. I., Brannan, A., Bates, F., Minko, T., and Discher, D. E. (2006a). Biodegradable polymersomes loaded with both paclitaxel and doxorubicin permeate and shrink tumors, inducing apoptosis in proportion to accumulated drug. J. Control. Release 116, 150-158. doi: 10.1016/j.jconrel.2006.07.012

Ahmed, F., Pakunlu, R. I., Srinivas, G., Brannan, A., Bates, F., Klein, M. L., et al. (2006b). Shrinkage of a rapidly growing tumor by drug-loaded polymersomes: pH-triggered release through copolymer degradation. Mol. Pharm. 3, 340-350. doi: $10.1021 / \mathrm{mp} 050103 \mathrm{u}$

Anajafi, T., Yu, J., Sedigh, A., Haldar, M. K., Muhonen, W. W., Oberlander, S., et al. (2017). Nuclear localizing peptide-conjugated, redox-sensitive polymersomes for delivering curcumin and doxorubicin to pancreatic cancer microtumors. Mol. Pharm. 14, 1916-1928. doi: 10.1021/acs.molpharmaceut.7b00014

Arrigo, A. (2000). sHsp as novel regulators of programmed cell death and tumorigenicity. Pathol. Biol. 48, 280-288.

Arrigo, A. P. (2005). In search of the molecular mechanism by which small stress proteins counteract apoptosis during cellular differentiation. J. Cell. Biochem. 94, 241-246. doi: 10.1002/jcb.20349

Arrigo, A. P., and Ducasse, C. (2002). Expression of the anti-apoptotic protein Hsp27 during both the keratinocyte differentiation and dedifferentiation of HaCat cells: expression linked to changes in intracellular protein organization? Exp. Gerontol. 37, 1247-1255. doi: 10.1016/S0531-5565(02)00131-6

Asano, I., So, S., and Lodge, T. P. (2016). Oil-in-oil emulsions stabilized by asymmetric polymersomes formed by $\mathrm{AC}+\mathrm{BC}$ block polymer co-assembly. J. Am. Chem. Soc. 138, 4714-4717. doi: 10.1021/jacs.6b01697

Battaglia, G., and Ryan, A. J. (2005). Bilayers and interdigitation in block copolymer vesicles. J. Am. Chem. Soc. 127, 8757-8764. doi: 10.1021/ja050742y

Blanazs, A., Massignani, M., Battaglia, G., Armes, S. P., and Ryan, A. J. (2009). Tailoring macromolecular expression at polymersome surfaces. Adv. Funct. Materials 19, 2906-2914. doi: 10.1002/adfm.200900201

Bodor, N. (1987). Redox drug delivery systems for targeting drugs to the braina. Ann. N. Y. Acad. Sci. 507, 289-306. doi: 10.1111/j.1749-6632.1987.tb45809.x

Cai, Y., Aubrecht, K. B., and Grubbs, R. B. (2011). Thermally induced changes in amphiphilicity drive reversible restructuring of assemblies of ABC triblock copolymers with statistical polyether blocks. J. Am. Chem. Soc. 133, 1058-1065. doi: $10.1021 /$ ja109262h

Cerritelli, S., Velluto, D., and Hubbell, J. A. (2007). PEG-SS-PPS: reductionsensitive disulfide block copolymer vesicles for intracellular drug delivery. Biomacromolecules 8, 1966-1972. doi: 10.1021/bm070085x

Chen, W., Meng, F., Cheng, R., and Zhong, Z. (2010). pH-Sensitive degradable polymersomes for triggered release of anticancer drugs: a comparative study with micelles. J. Control. Release. 142, 40-46. doi: 10.1016/j.jconrel.2009.09.023

Choucair, A., Lim Soo, P., and Eisenberg, A. (2005). Active loading and tunable release of doxorubicin from block copolymer vesicles. Langmuir 21, 9308-9313. doi: $10.1021 / 1 \mathrm{la} 050710$ o
Science Foundation of Shanghai, China (15ZR1432500), Projects of the Shanghai Committee of Science and Technology, China (No. 12XD1403800) and Funds for Interdisciplinary Projects of Medicine and Engineering of Shanghai JiaoTong University (No. YG2015MS06, YG2014QN06, and YG2016QN22), National Science and Technology Major Projects for Major New Drugs Innovation and Development (2017ZX09101005-0 08-002)
Christian, D. A., Cai, S., Bowen, D. M., Kim, Y., Pajerowski, J. D. and Discher, D. E. (2009). Polymersome carriers: from self-assembly to siRNA and protein therapeutics. Eur. J. Pharm. Biopharm. 71, 463-474. doi: 10.1016/j.ejpb.2008.09.025

Corti, A., Franzini, M., Paolicchi, A., and Pompella, A. (2010). Gammaglutamyltransferase of cancer cells at the crossroads of tumor progression, drug resistance and drug targeting. Anticancer Res. 30, 1169-1181.

Danhier, F., Vroman, B., Lecouturier, N., Crokart, N., Pourcelle, V., Freichels, H., et al. (2009). Targeting of tumor endothelium by RGD-grafted PLGAnanoparticles loaded with paclitaxel. J. Control. Release 140, 166-173. doi: 10.1016/j.jconrel.2009.08.011

Della Rocca, J., Huxford, R. C., Comstock-Duggan, E., and Lin, W. (2011). Polysilsesquioxane nanoparticles for targeted platin-based cancer chemotherapy by triggered release. Angew. Chem. Int. Ed. Engl. 50, 10330-10334. doi: 10.1002/anie.201104510

Discher, B. M., Won, Y. Y., Ege, D. S., Lee, J. C., Bates, F. S., Discher, D. E., et al. (1999). Polymersomes: tough vesicles made from diblock copolymers. Science 284, 1143-1146. doi: 10.1126/science.284.5417.1143

Discher, D. E., Ortiz, V., Srinivas, G., Klein, M. L., Kim, Y., Christian, D., et al. (2007). Emerging applications of polymersomes in delivery: from molecular dynamics to shrinkage of tumors. Prog. Polym. Sci. 32, 838-857. doi: 10.1016/j.progpolymsci.2007.05.011

Doherty, G. J., and McMahon, H. T. (2009). Mechanisms of endocytosis. Annu. Rev. Biochem. 78, 857-902. doi: 10.1146/annurev.biochem.78.081307.110540

Dou, H., Jiang, M., Peng, H., Chen, D., and Hong, Y. (2003). pHdependent self-assembly: micellization and micelle-hollow-sphere transition of cellulose-based copolymers. Angew. Chem. Int. Ed. Engl. 42, 1516-1519. doi: 10.1002/anie.200250254

Drummond, D. C., Meyer, O., Hong, K., Kirpotin, D. B., and Papahadjopoulos, D. (1999). Optimizing liposomes for delivery of chemotherapeutic agents to solid tumors. Pharmacol. Rev. 51, 691-744.

Du, J., and O'Reilly, R. K. (2009). Advances and challenges in smart and functiona polymer vesicles. Soft Matter 5, 3544-3561. doi: 10.1039/b905635a

Du, Y., Chen, W., Zheng, M., Meng, F., and Zhong, Z. (2012). pHsensitive degradable chimaeric polymersomes for the intracellular release of doxorubicin hydrochloride. Biomaterials 33, 7291-7299. doi: 10.1016/j.biomaterials.2012.06.034

Elloumi Hannachi, I., Itoga, K., Kumashiro, Y., Kobayashi, J., Yamato, M., and Okano, T. (2009). Fabrication of transferable micropatterned-cocultured cell sheets with microcontact printing. Biomaterials 30, 5427-5432. doi: 10.1016/j.biomaterials.2009.06.033

Fu, Z., Ochsner, M. A., de Hoog, H. P., Tomczak, N., and Nallani, M. (2011). Multicompartmentalized polymersomes for selective encapsulation of biomacromolecules. Chem. Commun. (Camb). 47, 2862-2864. doi: $10.1039 / \mathrm{c} 0 \mathrm{cc} 03971 \mathrm{c}$

Futaki, S. (2006). Oligoarginine vectors for intracellular delivery: design and cellular-uptake mechanisms. Peptide Sci. 84, 241-249. doi: 10.1002/bip.20421

Ge, X., Zhang, Q., Cai, Y., Duan, S., Chen, S., Lv, N., et al. (2014). PEG-PCL-DEX Polymersome-protamine vector as an efficient gene delivery system via PEGguided self-assembly. Nanomedicine 9, 1193-1207. doi: 10.2217/nnm.13.83

Giacomelli, C., Schmidt, V., and Borsali, R. (2007). Nanocontainers formed by selfassembly of poly (ethylene oxide)-b-poly (glycerol monomethacrylate)-drug conjugates. Macromolecules 40, 2148-2157. doi: 10.1021/ma062562u

Grabe, M., and Oster, G. (2001). Regulation of organelle acidity. J. Gen. Physiol. 117, 329-344. doi: 10.1085/jgp.117.4.329 
Gref, R., Lück, M., Quellec, P., Marchand, M., Dellacherie, E., Harnisch, S., et al. (2000). "Stealth"corona-core nanoparticles surface modified by polyethylene glycol (PEG): influences of the corona (PEG chain length and surface density) and of the core composition on phagocytic uptake and plasma protein adsorption. Colloids Surf. B. Biointerfaces 18, 301-313. doi: 10.1016/S0927-7765(99)00156-3

Grundl, T. (1994). A review of the current understanding of redox capacity in natural, disequilibrium systems. Chemosphere 28, 613-626. doi: 10.1016/0045-6535(94)90303-4

Gubernator, J. (2011). Active methods of drug loading into liposomes: recent strategies for stable drug entrapment and increased in vivo activity. Expert Opin. Drug Deliv. 8, 565-580. doi: 10.1517/17425247.2011.566552

Guo, J., Ogier, J. R., Desgranges, S., Darcy, R., and Caitriona, O. (2012). Anisamidetargeted cyclodextrin nanoparticles for siRNA delivery to prostate tumours in mice. Biomaterials 33, 7775-7784. doi: 10.1016/j.biomaterials.2012.07.012

Guo, X., Park, H., Liu, G., Liu, W., Cao, Y., Tabata, Y., et al. (2009). In vitro generation of an osteochondral construct using injectable hydrogel composites encapsulating rabbit marrow mesenchymal stem cells. Biomaterials 30, 2741-2752. doi: 10.1016/j.biomaterials.2009.01.048

Hammer, D. A., Robbins, G. P., Haun, J. B., Lin, J. J., Qi, W., Smith, L. A., et al. (2008). Leuko-polymersomes. Faraday Discuss. 139, 129-141. doi: $10.1039 / \mathrm{b} 717821 \mathrm{~b}$

Hvasanov, D., Wiedenmann, J., Braet, F., and Thordarson, P. (2011). Induced polymersome formation from a diblock PS-b-PAA polymer via encapsulation of positively charged proteins and peptides. Chem. Commun. (Camb). 47, 6314-6316. doi: 10.1039/c1cc11662b

Kim, H., Kang, Y. J., Kang, S., and Kim, K. T. (2012). Monosaccharide-responsive release of insulin from polymersomes of polyboroxole block copolymers at neutral pH. J. Am. Chem. Soc. 134, 4030-4033. doi: 10.1021/ja211728x

Kim, S. K., Foote, M. B., and Huang, L. (2012). The targeted intracellular delivery of cytochrome $\mathrm{C}$ protein to tumors using lipid-apolipoprotein nanoparticles. Biomaterials 33, 3959-3966. doi: 10.1016/j.biomaterials.2012.02.010

Kishimura, A., Koide, A., Osada, K., Yamasaki, Y., and Kataoka, K. (2007). Encapsulation of myoglobin in PEGylated polyion complex vesicles made from a pair of oppositely charged block ionomers: a physiologically available oxygen carrier. Angew. Chem. Int. Ed. 46, 6085-6088. doi: 10.1002/anie.200701776

Krack, M., Hohenberg, H., Kornowski, A., Lindner, P., Weller, H., and Förster, S. (2008). Nanoparticle-loaded magnetophoretic vesicles. J. Am. Chem. Soc. 130, 7315-7320. doi: $10.1021 / \mathrm{ja} 077398 \mathrm{k}$

Kricheldorf, H. R. (2006). Polypeptides and 100 years of chemistry of $\alpha$ amino acid N-carboxyanhydrides. Angew. Chem. Int. Ed. 45, 5752-5784. doi: 10.1002 /anie. 200600693

Kumar, M., Grzelakowski, M., Zilles, J., Clark, M., and Meier, W. (2007). Highly permeable polymeric membranes based on the incorporation of the functional water channel protein Aquaporin Z. Proc. Natl. Acad. Sci. U.S.A. 104, 20719-20724. doi: 10.1073/pnas.0708762104

Lee, H. J., Yang, S. R., An, E. J., and Kim, D. J. (2006). Biodegradable polymersomes from poly (2-hydroxyethyl aspartamide) grafted with lactic acid oligomers in aqueous solution. Macromolecules 39, 4938-4940. doi: 10.1021/ma060198t

Lee, J. S., Ankone, M., Pieters, E., Schiffelers, R. M., Hennink, W. E., and Feijen, J. (2011). Circulation kinetics and biodistribution of dual-labeled polymersomes with modulated surface charge in tumor-bearing mice: comparison with stealth liposomes. J. Control. Release 155, 282-288. doi: 10.1016/j.jconrel.2011.07.028

Lee, J. S., and Feijen, J. (2012). Polymersomes for drug delivery: design, formation and characterization. J. Control. Release 161, 473-483. doi: 10.1016/j.jconrel.2011.10.005

Levine, D. H., Ghoroghchian, P. P., Freudenberg, J., Zhang, G., Therien, M. J., Greene, M. I., et al. (2008). Polymersomes: a new multifunctional tool for cancer diagnosis and therapy. Methods 46, 25-32. doi: 10.1016/j.ymeth.2008.05.006

Li, B., Chen, G., Meng, F., Li, T., Yue, J., Jing, X., et al. (2012). A novel amphiphilic copolymer poly (ethylene oxide-co-allyl glycidyl ether)-graft-poly $(\varepsilon$-caprolactone): synthesis, self-assembly, and protein encapsulation behavior. Polym. Chem. 3, 2421-2429. doi: 10.1039/c2py20253k

Li, B., Qi, Y., He, S., Wang, Y., Xie, Z., Jing, X., et al. (2014). Asymmetric copolymer vesicles to serve as a hemoglobin vector for ischemia therapy. Biomater. Sci. 2, 1254-1261. doi: 10.1039/C4BM00123K
Li, F., Griffith, M., Li, Z., Tanodekaew, S., Sheardown, H., Hakim, M., et al. (2005). Recruitment of multiple cell lines by collagen-synthetic copolymer matrices in corneal regeneration. Biomaterials 26, 3093-3104. doi: 10.1016/j.biomaterials.2004.07.063

Li, X., Yang, W., Zou, Y., Meng, F., Deng, C., and Zhong, Z. (2015). Efficacious delivery of protein drugs to prostate cancer cells by PSMA-targeted pH-responsive chimaeric polymersomes. J. Control. Release. 220, 704-714. doi: 10.1016/j.jconrel.2015.08.058

Li, Y., Lokitz, B. S., and McCormick, C. L. (2006). Thermally responsive vesicles and their structural "locking" through polyelectrolyte complex formation. Angew. Chem. Int. Ed. 45, 5792-5795. doi: 10.1002/anie.200602168

Liu, G., Ma, S., Li, S., Cheng, R., Meng, F., Liu, H., et al. (2010). The highly efficient delivery of exogenous proteins into cells mediated by biodegradable chimaeric polymersomes. Biomaterials 31, 7575-7585. doi: 10.1016/j.biomaterials.2010.06.021

Liu, G. Y., Chen, C. J., and Ji, J. (2012). Biocompatible and biodegradable polymersomes as delivery vehicles in biomedical applications. Soft Matter 8, 8811-8821. doi: 10.1039/c2sm25721a

Liu, Q., Chen, J., and Du, J. (2014). Asymmetrical polymer vesicles with a "stealthy" outer corona and an endosomal-escape-accelerating inner corona for efficient intracellular anticancer drug delivery. Biomacromolecules 15, 3072-3082. doi: 10.1021/bm500676e

Liu, Q., Chen, S., Chen, J., and Du, J. (2015). An asymmetrical polymer vesicle strategy for significantly improving T 1 MRI sensitivity and cancer-targeted drug delivery. Macromolecules 48, 739-749. doi: 10.1021/ma502255s

Lomas, H., Canton, I., MacNeil, S., Du, J., Armes, S. P., Ryan, A. J., et al. (2007). Biomimetic $\mathrm{pH}$ sensitive polymersomes for efficient DNA encapsulation and delivery. Adv. Materials 19, 4238-4243. doi: 10.1002/adma.200700941

Lomas, H., Massignani, M., Abdullah, K. A., Canton, I., Lo Presti, C., MacNeil, S., et al. (2008). Non-cytotoxic polymer vesicles for rapid and efficient intracellular delivery. Faraday Discuss. 139, 143-159; discussion 213-228, 419-420. doi: 10.1039/b717431d

LoPresti, C., Lomas, H., Massignani, M., Smart, T., and Battaglia, G. (2009). Polymersomes: nature inspired nanometer sized compartments. J. Mater. Chem. 19, 3576-3590. doi: 10.1039/b818869f

Lu, L., Zou, Y., Yang, W., Meng, F., Deng, C., Cheng, R., et al. (2015). Anisamidedecorated $\mathrm{pH}$-sensitive degradable chimaeric polymersomes mediate potent and targeted protein delivery to lung cancer cells. Biomacromolecules 16, 1726-1735. doi: 10.1021/acs.biomac.5b00193

Massignani, M., Canton, I., Sun, T., Hearnden, V., MacNeil, S., Blanazs, A., et al. (2010a). Enhanced fluorescence imaging of live cells by effective cytosolic delivery of probes. PLoS ONE 5:e10459. doi: 10.1371/journal.pone.00 10459

Massignani, M., Lomas, H., and Battaglia, G. (2010b). "Polymersomes: a synthetic biological approach to encapsulation and delivery," in Modern Techniques for Nano-and Microreactors/-reactions, ed F. Caruso (Berlin; Heidelberg: Springer), $115-154$.

Massignani, M., LoPresti, C., Blanazs, A., Madsen, J., Armes, S. P., Lewis, A. L., et al. (2009). Controlling cellular uptake by surface chemistry, size, and surface topology at the nanoscale. Small 5, 2424-2432. doi: 10.1002/smll.200900578

Mecke, A., Dittrich, C., and Meier, W. (2006). Biomimetic membranes designed from amphiphilic block copolymers. Soft Matter 2, 751-759. doi: $10.1039 / \mathrm{b} 605165 \mathrm{k}$

Meng, F., Zhong, Y., Cheng, R., Deng, C., and Zhong, Z. (2014). pH-sensitive polymeric nanoparticles for tumor-targeting doxorubicin delivery: concept and recent advances. Nanomedicine 9, 487-499. doi: 10.2217/nnm.13.212

Meng, F., and Zhong, Z. (2011). Polymersomes spanning from nano-to microscales: advanced vehicles for controlled drug delivery and robust vesicles for virus and cell mimicking. J. Phys. Chem. Lett. 2, 1533-1539. doi: $10.1021 /$ jz200007h

Murdoch, C., Reeves, K. J., Hearnden, V., Colley, H., Massignani, M., Canton, I., et al. (2010). Internalization and biodistribution of polymersomes into oral squamous cell carcinoma cells in vitro and in vivo. Nanomedicine 5, 1025-1036. doi: $10.2217 / \mathrm{nnm} .10 .97$

Napoli, A., Boerakker, M. J., Tirelli, N., Nolte, R. J., Sommerdijk, N. A., and Hubbell, J. A. (2004b). Glucose-oxidase based self-destructing polymeric vesicles. Langmuir 20, 3487-3491. doi: 10.1021/la0357054 
Napoli, A., Valentini, M., Tirelli, N., Müller, M., and Hubbell, J. A. (2004a). Oxidation-responsive polymeric vesicles. Nat. Mater. 3, 183-189. doi: $10.1038 /$ nmat1081

Nardin, C., Hirt, T., Leukel, J., and Meier, W. (2000). Polymerized ABA triblock copolymer vesicles. Langmuir 16, 1035-1041. doi: 10.1021/la990951u

Nomani, A., Nosrati, H., Manjili, H. K., Khesalpour, L., and Danafar, H. (2017). Preparation and characterization of copolymeric polymersomes for protein delivery. Drug Res. doi: 10.1055/s-0043-106051. [Epub ahead of print].

Oerlemans, C., Bult, W., Bos, M., Storm, G., J., Nijsen, F. W., and Hennink, W. E. (2010). Polymeric micelles in anticancer therapy: targeting, imaging and triggered release. Pharm. Res. 27, 2569-2589. doi: 10.1007/s11095-010-0233-4

Ohya, Y., Takahashi, A., and Nagahama, K. (2011). "Biodegradable polymeric assemblies for biomedical materials," in Polymers in Nanomedicine, eds S. Kunugi, and T. Yamaoka (Berlin; Heidelberg: Springer), 65-114.

Onaca, O., Enea, R., Hughes, D. W., and Meier, W. (2009). Stimuli-responsive polymersomes as nanocarriers for drug and gene delivery. Macromol. Biosci. 9, 129-139. doi: 10.1002/mabi.200800248

Photos, P. J., Bacakova, L., Discher, B., Bates, F. S., and Discher, D. E. (2003). Polymer vesicles in vivo: correlations with PEG molecular weight. J. Control. Release 90, 323-334. doi: 10.1016/S0168-3659(03)00201-3

Qin, S., Geng, Y., Discher, D. E., and Yang, S. (2006). Temperaturecontrolled assembly and release from polymer vesicles of poly (ethylene oxide)-block-poly (N-isopropylacrylamide). Adv. Materials 18, 2905-2909. doi: 10.1002/adma.200601019

Rameez, S., Alosta, H., and Palmer, A. F. (2008). Biocompatible and biodegradable polymersome encapsulated hemoglobin: a potential oxygen carrier. Bioconjug. Chem. 19, 1025-1032. doi: 10.1021/bc700465v

Rerat, V., Pourcelle, V., Devouge, S., Nysten, B., and Marchand-Brynaert, J. (2010). Surface grafting on poly (ethylene terephthalate) track-etched microporous membrane by activation with trifluorotriazine: application to the biofunctionalization with GRGDS peptide. J. Polym. Sci. 48, 195-208. doi: $10.1002 /$ pola. 23778

Robbins, G. P., Saunders, R. L., Haun, J. B., Rawson, J., Therien, M. J., and Hammer, D. A. (2010). Tunable leuko-polymersomes that adhere specifically to inflammatory markers. Langmuir 26, 14089-14096. doi: 10.1021/la1017032

Rofstad, E. K., Mathiesen, B., Kindem, K., and Galappathi, K. (2006). Acidic extracellular $\mathrm{pH}$ promotes experimental metastasis of human melanoma cells in athymic nude mice. Cancer Res. 66, 6699-6707. doi: 10.1158/0008-5472.CAN-06-0983

Sanson, C., Schatz, C., Le Meins, J. F., Soum, A., Thévenot, J., Garanger, E., et al. (2010). A simple method to achieve high doxorubicin loading in biodegradable polymersomes. J. Control. Release 147, 428-435. doi: 10.1016/j.jconrel.2010.07.123

Schrama, D., Reisfeld, R. A., and Becker, J. C. (2006). Antibody targeted drugs as cancer therapeutics. Nat. Rev. Drug Discov. 5, 147-159. doi: 10.1038/nrd1957

Stano, A., Scott, E. A., Dane, K. Y., Swartz, M. A., and Hubbell, J. A. (2013). Tunable $\mathrm{T}$ cell immunity towards a protein antigen using polymersomes vs. solid-core nanoparticles. Biomaterials 34, 4339-4346. doi: 10.1016/j.biomaterials.2013.02.024

Stoenescu, R., Graff, A., and Meier, W. (2004). Asymmetric ABC-triblock copolymer membranes induce a directed insertion of membrane proteins. Macromol. Biosci. 4, 930-935. doi: 10.1002/mabi.200400065

Sun, H., Guo, B., Cheng, R., Meng, F., Liu, H., and Zhong, Z. (2009). Biodegradable micelles with sheddable poly (ethylene glycol) shells for triggered intracellular release of doxorubicin. Biomaterials 30, 6358-6366. doi: 10.1016/j.biomaterials.2009.07.051

Tan, M. L., Choong, P. F., and Dass, C. R. (2010). Recent developments in liposomes, microparticles and nanoparticles for protein and peptide drug delivery. Peptides 31, 184-193. doi: 10.1016/j.peptides.2009.10.002

Tew, K. D. (2007). Redox pathways in cancer drug discovery. Curr. Opin. Pharmacol. 7:353. doi: 10.1016/j.coph.2007.07.003

Torchilin, V., Levchenko, T., Lukyanov, A., Khaw, B., Klibanov, A., Rammohan, R., et al. (2001). p-Nitrophenylcarbonyl-PEG-PE-liposomes: fast and simple attachment of specific ligands, including monoclonal antibodies, to distal ends of PEG chains via p-nitrophenylcarbonyl groups. Biochim. Biophys. Acta 1511, 397-411. doi: 10.1016/S0005-2728(01)00165-7

Torchilin, V. P., and Lukyanov, A. N. (2003). Peptide and protein drug delivery to and into tumors: challenges and solutions. Drug Discov. Today 8, 259-266. doi: 10.1016/S1359-6446(03)02623-0

van Dongen, S. F., de Hoog, H. P., Peters, R. J., Nallani, M., Nolte, R. J., and van Hest, J. C. (2009). Biohybrid polymer capsules. Chem. Rev. 109, 6212-6274. doi: $10.1021 /$ cr900072y

Velonia, K., Rowan, A. E., and Nolte, R. J. (2002). Lipase polystyrene giant amphiphiles. J. Am. Chem. Soc. 124, 4224-4225. doi: 10.1021/ja017809b

Wang, L., Chierico, L., Little, D., Patikarnmonthon, N., Yang, Z. Azzouz, M., et al. (2012). Encapsulation of biomacromolecules within polymersomes by electroporation. Angew. Chem. Int. Ed. 51, 11122-11125. doi: 10.1002/anie.201204169

Wang, X., Sun, H., Meng, F., Cheng, R., Deng, C., and Zhong, Z. (2013). Galactose-decorated reduction-sensitive degradable chimaeric polymersomes as a multifunctional nanocarrier to efficiently chaperone apoptotic proteins into hepatoma cells. Biomacromolecules 14, 2873-2882. doi: 10.1021/bm4007248

Williams, D., van der Weijden, J., van Oers, M., Abdelmohsen, L., Peng, F., Wilson, D., et al. (2017). "Functional polymersomes for application in nanomedicine," in 14th Annual UNESCO/IUPAC Conference on Macromolecules and Materials (Stellenbosch).

Xiong, X. Y., Li, Y. P., Li, Z. L., Zhou, C. L., Tam, K. C., Liu, Z. Y., et al. (2007). Vesicles from Pluronic/poly (lactic acid) block copolymers as new carriers for oral insulin delivery. J. Control. Release 120, 11-17. doi: 10.1016/j.jconrel.2007.04.004

$\mathrm{Xu}, \mathrm{H}$., Meng, F., and Zhong, Z. (2009). Reversibly crosslinked temperatureresponsive nano-sized polymersomes: synthesis and triggered drug release. $J$. Mater. Chem. 19, 4183-4190. doi: 10.1039/b901141b

Yang, J., Bei, J., and Wang, S. (2002). Enhanced cell affinity of poly (D,L-lactide) by combining plasma treatment with collagen anchorage. Biomaterials 23, 2607-2614. doi: 10.1016/S0142-9612(01)00400-8

Yang, M., Wang, W., Yuan, F., Zhang, X., Li, J., Liang, F., et al. (2005). Soft vesicles formed by diblock codendrimers of poly(benzyl ether) and poly(methallyl dichloride). J. Am. Chem. Soc. 127, 15107-15111. doi: 10.1021/ja052713t

Yin, H., Kang, S. W., and Bae, Y. H. (2009). Polymersome formation from AB2 type 3-miktoarm star copolymers. Macromolecules 42, 7456-7464. doi: 10.1021/ma901701w

Zhang, L., and Eisenberg, A. (1995). Multiple morphologies of "Crew-Cut" aggregates of polystyrene-b-poly(acrylic acid) block copolymers. Science 268, 1728-1731. doi: 10.1126/science.268.5218.1728

Zhang, Y., Wu, F., Yuan, W., and Jin, T. (2010). Polymersomes of asymmetric bilayer membrane formed by phase-guided assembly. J. Control. Release 147, 413-419. doi: 10.1016/j.jconrel.2010.07.121

Zhao, L., Li, N., Wang, K., Shi, C., Zhang, L., and Luan, Y. (2014). A review of polypeptide-based polymersomes. Biomaterials 35, 1284-1301. doi: 10.1016/j.biomaterials.2013.10.063

Zhou, W., Meng, F., Engbers, G. H., and Feijen, J. (2006). Biodegradable polymersomes for targeted ultrasound imaging. J. Control. Release 116, e62-64. doi: 10.1016/j.jconrel.2006.09.051

Zupancich, J. A., Bates, F. S., and Hillmyer, M. A. (2006). Aqueous dispersions of poly (ethylene oxide)-b-poly ( $\gamma$-methyl- $\varepsilon$-caprolactone) block copolymers. Macromolecules 39, 4286-4288. doi: 10.1021/ma060642s

Conflict of Interest Statement: The authors declare that the research was conducted in the absence of any commercial or financial relationships that could be construed as a potential conflict of interest.

Copyright (c) 2017 Zhao, Li, Zhao, Yang, Li, Zhou and Yuan. This is an open-access article distributed under the terms of the Creative Commons Attribution License (CC $B Y)$. The use, distribution or reproduction in other forums is permitted, provided the original author(s) or licensor are credited and that the original publication in this journal is cited, in accordance with accepted academic practice. No use, distribution or reproduction is permitted which does not comply with these terms. 